\title{
Glycopyrrolate and formoterol fumarate for the treatment of COPD
}

\author{
Pierre-Edouard Grilletta, , Cosette Le Souder ${ }^{\mathrm{c}}$, Juliette Rohou ${ }^{\mathrm{a}, \mathrm{b}}$, Olivier Cazorla, Jérémy Charriot \\ and Arnaud Bourdin ${ }^{a, b}$ \\ aPhyMedExp, University of Montpellier, INSERM U1046, CNRS UMR, Montpellier, France; 'bepartment of Respiratory Diseases, CHU Montpellier, \\ University of Montpellier, Montpellier, France; 'Pharmacovigilance Regional Center, Medical Pharmacology and Toxicology Department, CHU \\ Montpellier, Montpellier, France
}

\begin{abstract}
Introduction: Long acting bronchodilators are nowadays the central treatment for management of stable COPD. Several combinations exist within the market with different formulation devices. This article reviews a recent dual combination of glycopyrronium and formoterol fumarate in an innovative pMDI-fixed dual combination, Bevespi ${ }^{\circledast}$ Aerosphere.

Areas covered: This article explored the literature to understand the place of this novel combination and unique delivery drug device in today's therapeutic arsenal. Clinical efficacy and safety have been evaluated through the different clinical trials published in public databases.

Expert opinion: Within the fixed-dose combinations, Glycopyrrolate and formoterol fumarate offer a credible unique $\mathrm{pMDI}$ option to be given twice a day. LABA-LAMA offers an ICS-free alternative in COPD pharmacology which represents an important treatment option given the current debate over whether or not, maintenance triple therapy combined with ICS are benefic in the long term.
\end{abstract}

\section{KEYWORDS} Bronchodilators; COPD; pMDI

\section{Introduction}

Chronic Obstructive Pulmonary Disease or COPD is one of the major causes of death worldwide, reaching third rank in many industrialized countries such as USA[1] causing a high social and economic burden [2]. The long-term exposure to noxious particles and gas causes small airway disease associated with parenchymal destruction, leading to emphysema and airflow limitation [1]. Several strategies are proposed to improve quality of life and health status of patients through non-pharmacological and pharmacological methods: smoking cessation, vaccinations, activity, management of comorbidities and pharmacotherapy [1] with the aim of reducing symptoms and frequency/severity of exacerbations. Pharmacotherapy includes bronchodilators, i.e. anticholinergic, $\beta-2$ adrenergic or methylxanthines, inhaled corticosteroids as anti-inflammatory, anti-PDE4, antibiotics and mucolytics [1]. The management of stable COPD requires maintenance treatment with long-acting bronchodilators with evidence indicating that the co-administration of two different classes (long acting muscarinic antagonist, i.e. LAMA and long-acting beta-2 agonist, i.e. LABA) improves lung function and symptoms, better than when taken individually. Therefore, this article reviews a recent dual combination of LAMA and LABA named Bevespi Aerosphere ${ }^{\text {TM }}$ (AstraZeneca), a fixed dose combination of glycopyrrolate and formoterol fumarate in a pressurized metered dose inhaler (pMDI).

\section{Overview of the market}

\subsection{Unmet needs of currently available therapies?}

COPD is a devastating and poorly recognized disease. Although it is now ranked in the leading causes of deaths worldwide with prevalence-reaching levels of at least $10 \%$ of the population [3], the diagnosis is still poorly understood and known by the general population. Beyond the active controversy regarding diagnostic issues, three pathologic pillars are now clearly established: 1) symptoms of chronic bronchitis mostly related to goblet cell hyperplasia and impaired mucociliary clearance, 2) centrilobular emphysematous destruction of the alveolar compartment now seen as a consequence of small airways obstruction by peribronchiolar fibrosis, mucus plugging, inflammatory infiltrate and increased smooth muscle tone, and 3) irreversible or poorly reversible chronic airflow obstruction as measured by spirometry, as a consequence of the first two mechanisms [1]. Chronic respiratory failure with a certain degree of pulmonary hypertension is the classical end stage of the disease in contrast to other chronic airway diseases such as asthma. Outcomes in COPD are complex and multiple and not necessarily similar among all patients given the heterogeneity of the disease. For example, comorbidities are a major cause of disability and death but these outcomes are rarely addressed in clinical trials. Currently, accelerated lung function decline and development of chronic respiratory failure and death, episodes of exacerbations and hospital admissions, respiratory handicap and poor quality of life are outcomes that are partially addressed by the 
Article highlights

- Glycopyrronium and formoterol fumarate (GFF) is the only LAMA LABA fixed combination formulated as a metered dose inhaler (MDI) delivered through an Aerosphere inhaler available.

- GFF improves lung function through forced expiratory volume in $1 \mathrm{~s}$ $\left(\mathrm{FEV}_{1}\right)$ and inspiratory capacity (IC) better than placebo and monocomponents taken individually.

- GFF reduces the use of rescue medication, improves dyspnea and the quality of life.

- GFF is as safe as its comparators.

- The association of GFF to ICS needs to be discussed as new combination of GFF and ICS have been tested in phase III and approved in COPD maintenance therapy.

currently available therapeutic options, although there are still some improvements needed to ideally manage these outcomes. Frequently associated comorbidities such as cardiovascular impairment, lung cancer, pulmonary fibrosis, depression, osteoporosis, etc. should also be ideally prevented by currently developed drugs even though impacting the natural history of the disease remains quite elusive at this stage.

Managing COPD in 2020 mostly relies on non-pharmacological aspects such as rehabilitation, smoking cessation, vaccines, oxygen supplementation when appropriate (and this should be cautiously weighed nowadays) and lung volume reduction when feasible. Most of the pharmacological goals target lung function, quality of life, and reduction of the exacerbation rates. The latter is now progressively better understood with the recognition that some T2 patterns can be evidenced in a subset of COPD patients, leading to studies assessing the benefits of T2-targeting biologics that are already approved in asthma [4]; long-term macrolides may also be recommended. Theophylline used to be recommended as a bronchodilator and has some anti-inflammatory effects, though anti-inflammatory potency is greater with modern phosphodiesterase 4 inhibitors. Table 1 summarizes the currently available therapeutic options, the current unmet needs and related outcomes. Although it would be difficult to compile all available data and decide whether or not post hoc studies or meta-analysis and other study types should be taken into account, the main objective of this table is highlighting to which extent currently available options cover the real unmet need in COPD.

\subsection{Competitor compounds/classes of compounds in clinic or late development}

Thus far, five different FDCs of LAMA/LABA are available worldwide (Table 2), three of them are dry-powder inhaler (DPI), one is a soft-mist inhaler (SMI) and only one (glycopyrrolate/formoterol fumarate) is a metered dose inhaler (MDI).

\subsection{Chemistry}

Glycopyrronium bromide corresponds to the molecular formula $\mathrm{C}_{19} \mathrm{H}_{28} \mathrm{BrNO}_{3}$. Its molecular mass is $398.3 \mathrm{~g} / \mathrm{mol}$ and it has the structure seen in Figure 1.

It is a white crystalline powder, soluble in water and ethanol with two chiral centers.

Formoterol fumarate dihydrate corresponds to the molecular formula $\mathrm{C}_{42} \mathrm{H}_{52} \mathrm{~N}_{4} \mathrm{O}_{12} \cdot 2 \mathrm{H}_{2} \mathrm{O}$. Its molecular mass is $840.91 \mathrm{~g} /$ mol and it has the structure seen in Figure 2.

It is a white or slightly yellow powder, slightly soluble in water and soluble in methanol.

The finished medical product of glycopyrronium/formoterol fumarate is a pressurized, micronized suspension designed for inhalation, also referred to as pMDI. The drug is stabilized in a fixed dose combination, using 'porous particles' made of 1,2-diasteroyl-sn-glycero-3-phosphocholine (DSPC) and calcium chloride dihydrate according to the manufacturer AstraZeneca. DSPC is also used in other devices combined with calcium chloride dihydrate such as an inhaler for

Table 1. Unmet needs and pharmacological therapies in COPD. Legend: ' $y$ ': positive effect; ' $x$ ': negative effect or not evaluated. BDI/TDI: baseline dyspnea index/ transition dyspnea index; CAT: COPD assessment test; FEV1: forced expiratory volume in 1 second; ICS: inhaled corticosteroids; ICU: intensive care unit; IPDE4: inhibitor of phosphodiesterase 4; LABA: long-acting beta-2 adrenergic; LAMA: long-acting muscarinic antagonist; QoL: quality of life; 6MWD: 6-minutes walking distance.

\begin{tabular}{|c|c|c|c|c|c|c|c|c|c|c|c|}
\hline Unmet needs & Assessable Outcomes & LAMA & LABA & $\begin{array}{c}\text { ICS } \\
\text { LABA }\end{array}$ & $\begin{array}{l}\text { LAMA } \\
\text { LABA }\end{array}$ & $\begin{array}{l}\text { ICS LAMA } \\
\text { LABA }\end{array}$ & Theophylline & $\begin{array}{c}\text { T2 } \\
\text { biologics }\end{array}$ & IPDE4 & Macrolides & Vaccines \\
\hline \multirow{4}{*}{$\begin{array}{l}\text { Chronic airflow } \\
\text { impairment } \\
\text { Symptoms }\end{array}$} & FEV1 & y & $y$ & $\mathrm{y}$ & y & $y$ & $y$ & $x$ & y & $x$ & $x$ \\
\hline & Accelerated FEV1 decline & $x$ & $x$ & $x$ & $x$ & $y$ & $x$ & $x$ & $x$ & $x$ & $x$ \\
\hline & CAT & y & $y$ & $y$ & y & $y$ & $y$ & $x$ & $x$ & $x$ & $x$ \\
\hline & Dyspnea (BDI/TDI) & $y$ & $y$ & $y$ & $y$ & $y$ & $x$ & $x$ & $x$ & $x$ & $x$ \\
\hline \multirow[t]{3}{*}{ Handicap } & 6MWD & y & $y$ & $\mathrm{y}$ & $y$ & $y$ & $x$ & $x$ & $x$ & $x$ & $x$ \\
\hline & QoL & y & y & y & $y$ & $y$ & $x$ & $x$ & $x$ & $x$ & $x$ \\
\hline & $\begin{array}{l}\text { Longterm oxygen therapy } \\
\text { requirement } \\
\text { Lung transplantation }\end{array}$ & $x$ & $x$ & $x$ & $x$ & $x$ & $x$ & $x$ & $x$ & $x$ & $x$ \\
\hline \multirow[t]{3}{*}{ Exacerbations } & Non severe & y & y & y & y & y & $x$ & $y$ & y & y & y \\
\hline & Severe & $y$ & $y$ & $y$ & y & $y$ & $x$ & $y$ & $y$ & $y$ & $y$ \\
\hline & ICU admissions & $x$ & $x$ & $\mathrm{x}$ & $x$ & $x$ & $x$ & $x$ & $x$ & $x$ & $x$ \\
\hline \multirow[t]{2}{*}{ Death } & Respiratory related & $x$ & $x$ & $\mathrm{x}$ & $x$ & y & $x$ & $x$ & $x$ & $x$ & $x$ \\
\hline & Non respiratory related & $x$ & $x$ & $x$ & $x$ & $y$ & $x$ & $x$ & $x$ & $x$ & $x$ \\
\hline \multirow[t]{7}{*}{ Comorbidities } & Depression & $x$ & $x$ & $x$ & $x$ & $x$ & $x$ & $x$ & $x$ & $x$ & $x$ \\
\hline & Lung cancer & $x$ & $x$ & $x$ & $x$ & $x$ & $x$ & $x$ & $x$ & $x$ & $x$ \\
\hline & Pulmonary fibrosis & $x$ & $x$ & $\mathrm{x}$ & $x$ & $x$ & $x$ & $x$ & $x$ & $x$ & $x$ \\
\hline & Pulmonary hypertension & $x$ & $x$ & $\mathrm{x}$ & $x$ & $x$ & $x$ & $x$ & $x$ & $x$ & $x$ \\
\hline & Cardiovascular & $x$ & $x$ & $x$ & $y$ & $x$ & $x$ & $x$ & $x$ & $x$ & $x$ \\
\hline & Osteoporosis & $x$ & $x$ & $x$ & $x$ & $x$ & $x$ & $x$ & $x$ & $x$ & $x$ \\
\hline & Cachexia - myopathy & $x$ & $x$ & $x$ & $x$ & $x$ & $x$ & $x$ & $x$ & $x$ & $x$ \\
\hline
\end{tabular}


Table 2. FDCs LAMA/LABA association available [1]. Legend: DPI: dry powder inhaler; MDI: metered dose inhaler; SMI: soft mist inhaler.

\begin{tabular}{|c|c|c|}
\hline Molecules (Brand names) & $\begin{array}{l}\text { Inhaler } \\
\text { type }\end{array}$ & $\begin{array}{l}\text { Duration of } \\
\text { action }\end{array}$ \\
\hline $\begin{array}{l}\text { indacaterol/glycopyrronium } \\
\text { (Ultibro }{ }^{\odot} \text { Breezhaler) }\end{array}$ & DPI & $12-24 \mathrm{~h}$ \\
\hline vilanterol/umeclidinium (Anoro ${ }^{\circledR}$ Ellipta) & DPI & $24 \mathrm{~h}$ \\
\hline formoterol/aclidinium (Duaklir® Pressair) & DPI & $12 \mathrm{~h}$ \\
\hline $\begin{array}{l}\text { formoterol/glycopyrronium (Bevespi }{ }^{\oplus} \\
\text { Aerosphere) }\end{array}$ & MDI & $12 \mathrm{~h}$ \\
\hline olodaterol/tiotropium (Spiolto ${ }^{\circledR}$ Respimat). & SMI & $24 \mathrm{~h}$ \\
\hline
\end{tabular}

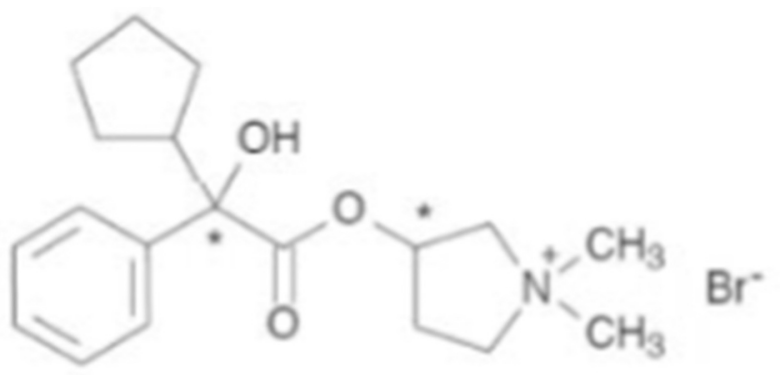

Figure 1. Chemical structure of glycopyrronium bromide.

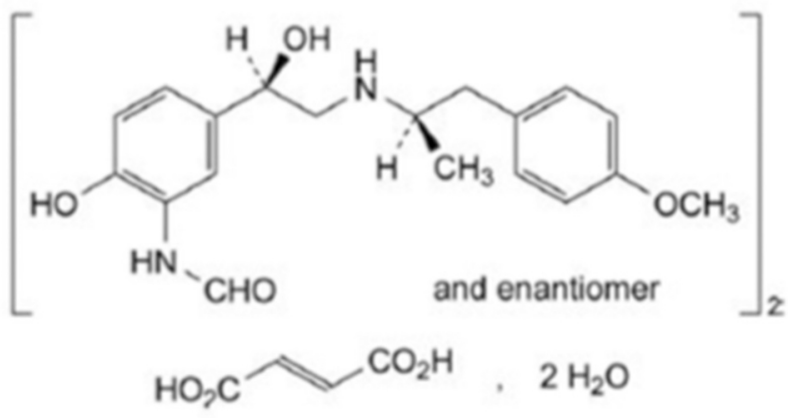

Figure 2. Chemical structure of formoterol fumarate dihydrate.

tobramycin (Tobi-Podhaler ${ }^{\mathrm{TM}}$ ) marketed by Novartis since 2013 or with other excipients like cholesterol in DaunoXome ${ }^{\circledR}$ (Nexstar Pharmaceuticals, USA) [5,6]. The propellant used for inhalation is norflurane [7]. The porous particles are used as a suspension-forming agent preventing the sedimentation of the micronized active agents suspended in the propellant. Calcium chloride improves the stability of the suspension $[6,7]$. This innovative co-suspension delivery technology avoids the use of co-solvents and other suspension stabilizers and permits the use of two or more drugs inside a MDI, which represents the most widely used aerosol delivery device worldwide $[5,6]$.

\subsection{Drug delivery device and aerodynamic properties}

The aerosol performance was tested according to United States Pharmacopoeia, with assessment of aerodynamic particle size distribution (aPSD), mass median aerodynamic diameter (MMAD) and fine particle fraction (FPF) [6]. Comparison between dual fixed drug combination (GFF MDI) and monocomponent (GP MDI and FF MDI) for aPSD and FPF exhibited no differences between devices. The MMADs were 3.0 and $3.1 \mu \mathrm{m}$ for GFF MDI compared to $3.2 \mu \mathrm{m}$ for GP and FF $\mathrm{MDI}$, illustrating no difference between devices. The MDI device was also tested within a range of continuous in vitro flow rates of 15 to $90 \mathrm{~L} / \mathrm{min}$, displaying 61 to $69 \%$ of FPF between 30 and $90 \mathrm{~L} / \mathrm{min}$ and $48 \%$ at $15 \mathrm{~L} / \mathrm{min}$. These results demonstrate the performance of the drug device across a wide range of flow rates, similar to other MDIs but superior to DPI to the extent that it is usable in lower flow rates [6]. Nevertheless, pMDI still needs a proper hand-mouth coordination in order to provide an effective dose distribution.

Pulmonary deposition assessed by gamma scintigraphy in healthy patients $(n=10)$ displayed that $38.4 \%$ of the emitted dose (representing $89.9 \%$ of the metered dose, after withdrawal of the dose found in the actuator) of GFF MDI particles reached the lungs whereas very few particles were exhaled $(<0.25 \%)$. The remaining emitted dose was mainly delivered to the oropharyngeal and stomach regions (61.4\%). Both central and peripheral depositions were noted with the central being slightly predominant (ratio outer/inner of 0.57) [8]. This result confirmed that the particles, designed in this original technology device, can reach the deep lung regions and small airways, an outcome that is known to be of interest in COPD. Although the scintigraphy deposition technique remains poorly accurate in terms of quantification [9], the association of this method with aerosol performance in vitro (US Pharmacopoeia techniques) provide good information of the capacity of GFF pMDI to reach its targets within the lungs.

\subsection{Pharmacodynamics}

The combination of glycopyrronium bromide and formoterol fumarate is an association of two different bronchodilators, a long-acting muscarinic antagonist (LAMA, for glycopyrronium bromide) and a long-acting beta 2 agonist (LABA, for formoterol fumarate) $[1,7]$.

Glycopyrronium bromide acts through the inhibition of muscarinic receptors, with a similar affinity from M1 to M5 subtypes. In the COPD indication, the pharmacological effect is supposedly provided by the M3 inhibition subtype on the airway smooth muscle, leading to bronchodilation.

The effect of formoterol fumarate is supported by beta- 2 adrenergic receptor binding, causing an increase in the intracellular cyclic adenosine monophosphate (AMPc) level via the adenylate cyclase activation, leading to rapid bronchodilation. In vitro studies have shown that formoterol fumarate is 100 times more specific to type 2 beta receptors when compared to type 1 [7].

The synergy of two different drugs acting on two distinct receptors leading to a cumulative effect on relaxation of smooth muscle cells surrounding bronchus, is also supported by the differential density of these receptors. Indeed, muscarinic receptors are more likely located in central airways whereas 32 adrenoreceptors may be more common in peripheral airways, suggesting that glycopyrronium would be more efficient centrally and formoterol peripherally [7]. This impact on both compartments of the lung may explain the benefits 
observed on lung function, which is superior to the simple addition of the components assessed individually [10-12].

A phase IIIB crossover clinical trial (NCT02643082) assessed functional respiratory imaging of 20 moderate-to-severe COPD patients after 15 days of twice daily administration of glycopyrrolate/formoterol MDI. The results of this study showed an improvement in specific image-based airway volume (siVaw) of $75 \%$ and a reduction in specific image-based airway resistance (siRaw) of $71 \%$ compared to placebo MDI, which were the co-primary endpoints (both $p<0.0001$ ). Those improvements with the GFF treatment were accompanied by significant amelioration from baseline of post-dose FEV (forced $_{1}$ expiratory volume in 1 second), inspiratory capacity, forced vital capacity, functional residual capacity and residual volumes compared to placebo (all $p<0.001$ ) [13].

The pharmacology cardiovascular safety profile of the mono and the combined drug have been looked at over several years. The GFF combination has been studied for cardiac safety in different clinical trials without highlighting statistical differences on any cardiac outcomes [10-12,14,15]. Among these trials, two different studies have focused specifically on cardiac safety. The NCT01854658 trial, known as PINNACLE-2, included a subset of patients who participated in a 24-hour Holter sub-study. The NCT01349803 trial was a cardiovascular safety phase I including a Thorough QT (TQT) study. In the PINNACLE-2 Holter sub-study, including 585 COPD patients using GFF MDI for a period of 24 weeks, no difference was shown compared to placebo and open-label tiotropium among the different sub-study outcomes: change from baseline in 24-hour mean heart rate, mean daytime and night time heart rates, maximum and minimum 24-hour means or frequency of ventricular, supraventricular events and atrial fibrillation [11]. The TQT phase I study included 70 healthy volunteers in a single dose, five arm, crossover, placebo and moxifloxacin-controlled trial. The results of this study showed a largest least squares mean (LSM) placebo-corrected change in QTcl of $7.6 \mathrm{msec}$ for the highest GFF dosage (144/ $38.4 \mu \mathrm{g}$ ). This value had a confidence interval below the 10 msec criteria interval for negative TQT-study according to $\mathrm{ICH}$ E14 [15]. It has to be mentioned that the approved dose for GFF is $18 / 9.6 \mu \mathrm{g}$ twice daily, far below the highest dosage tested for this TQT-study.

\subsection{Pharmacokinetics and metabolism}

Glycopyrronium bromide and formoterol fumarate are two well-known drugs and therefore their pharmacokinetics are extensively described in literature. Nevertheless, the combination of the two drugs has been studied to describe the pharmacokinetics of the association as a comparison of each mono-component.

The pharmacokinetic properties of both molecules used in combination (GFF MDI) following the inhalation are similar to mono-components taken individually in terms of $\mathrm{AUC}_{0-12}$ in single dose or at steady-state and $C_{\max }[7,16]$. A pharmaco-kinetic sub-study of PINNACLE-1, with 292 COPD patients determined comparable systemic accumulation between GFF MDI and individually taken monocomponents after 12 weeks of chronic dosing. The relative bioavailability assessed by $\mathrm{AUC}_{0-12}$ (glycopyrronium $100.6 \%$, formoterol $100.91 \%$ ) and $C_{\max }$ (glycopyrronium $109.10 \%$, formoterol $101.3 \%$ ) were also similar between the combination formulation and the mono-components with confidence intervals generally spread within the bounds of $80-125 \%$ [17]. A pharmacokinetic study was performed in a Japanese population of healthy subjects and discovered no differences between GFF combination and GP mono-product, nor interaction of drugs used in combination [18].

A randomized phase III study (NCT02454959) explored the impact of the utilization of a valved holding chamber (VHC) for GFF MDI administration in 80 COPD patients. The study showed similar efficacy, with similar PK parameters but slightly higher concentrations of glycopyrronium when using the $\mathrm{VHC}$, although this was not considered to be a clinically significant increase. The systemic exposure of GP was 115.99\% [99.74-134.89] with the VHC device compared to without, and no difference was highlighted for formoterol fumarate [19].

\subsubsection{Absorption}

After inhaled administration of the dual combination, the maximum concentration $\left(C_{\max }\right)$ was obtained as early as 5 minutes for glycopyrronium and 20 to 60 minutes for formoterol. The steady state is obtained after 2 to 3 days [16] of chronic administration and the systemic accumulation ratio is 2.30 for glycopyrronium and 1.52 for formoterol [17].

\subsubsection{Distribution}

Glycopyrronium has a $741 \mathrm{~L}$ central volume of distribution and a $2990 \mathrm{~L}$ peripheral volume of distribution, with a 43 to $54 \%$ binding percentage to plasma proteins [7].

Formoterol has $1030 \mathrm{~L}$ and $647 \mathrm{~L}$ of central and peripheric volume distribution, respectively, with a 46 to $58 \%$ binding percentage to plasma proteins [7].

\subsubsection{Metabolism}

The elimination of glycopyrronium is principally done through renal excretion and slightly by metabolism via the cytochrome isoform CYP2D6.

Formoterol is eliminated via direct glucuronidation and O-demethylation followed by conjugation into inactive metabolites using CYP2D6 and possibly CYP2C19 and CYP2C9. A second pathway involves deformylation, and sulfate conjugation.

In vitro studies do not indicate any inhibition or induction of cytochromes by either glycopyrronium or formoterol $[7,16]$.

\subsubsection{Elimination}

The half-life of glycopyrronium following oral inhalation is 15 hours. IV administration showed that $85 \%$ of the dose was recovered in urine, and the clearance of glycopyrronium was $124 \mathrm{~L} / \mathrm{h}$.

The half-life of formoterol following oral inhalation is 13 hours. IV administration showed that $62 \%$ of the dose was recovered in urine and $24 \%$ in the feces and the clearance of formoterol was $99 \mathrm{~L} / \mathrm{h} \mathrm{[16].}$

Terminal half-life of glycopyrronium and formoterol fumarate combination at the recommended dose level (GFF 18/ $9.6 \mu \mathrm{g})$ have been evaluated using population PK models and 


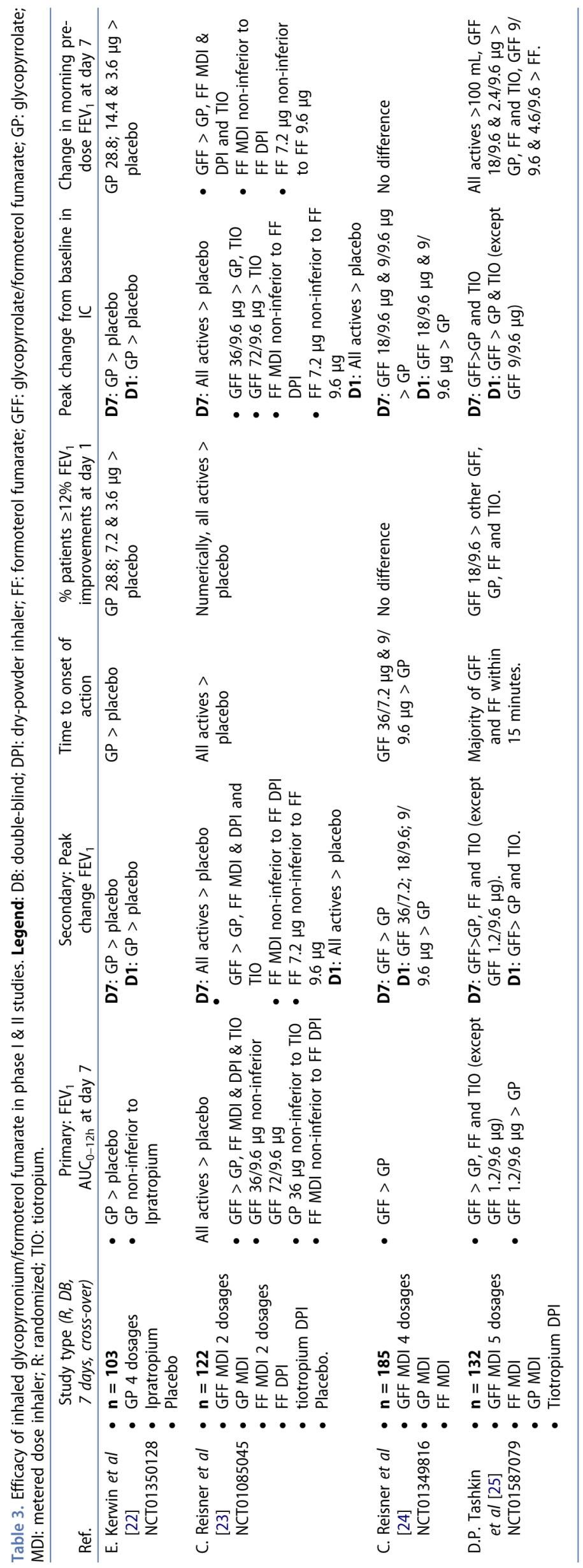


is estimated around 15 hours for glycopyrronium and 13 hours for formoterol [7].

All studies have been only performed on patients with a renal function between 30 and $196 \mathrm{~mL} / \mathrm{min}$ of estimated glomerular filtration rate (eGFR) and indicated an increase in GP $\mathrm{AUC}_{0-12}$ of $30 \%$ in patients with mild-to-moderate renal impairment (eGFR $30-45 \mathrm{~mL} / \mathrm{min}$ ) $[7,16]$. For patients with severe and end-stage renal impairment, no studies have been conducted, and the recommendations are to treat with GFF only 'if the expected benefit overweighs the potential risk' [16].

Similarly, as formoterol metabolism is mainly driven by the liver, a higher exposure is expected in patients with hepatic impairment, but no studies have been conducted in this specific population $[7,16]$.

\subsubsection{Linearity and interactions}

Dose-linearity studies have shown that pharmacokinetics follow a linear trend for both glycopyrronium (from 14.4 to $115.2 \mu \mathrm{g}$ ) and formoterol (from 2.4 to $19.2 \mu \mathrm{g}$ ) [16] when used separately.

Overall, studies have not shown any drug interactions between the drugs in co-administration in vivo $[7,17]$. One study explored the drug interaction between glycopyrronium alone and cimetidine, an inhibitor of the organic cation transporter 2 (OCT 2). This study did not highlight clinically relevant modifications deserving a need to adapt the posology of either glycopyrronium alone or cimetidine [20]. Another study was conducted using a triple therapy with glycopyrronium/formoterol fumarate/beclometasone (BDP/FF/GB) with similar results, exhibiting no clinical interference between cimetidine and BDP/FF/GB through OCT2 [21]. However, those studies did not explore the interaction within the GFF combination.

\section{Clinical efficacy}

\subsection{Phase I \& ||}

Several dosing studies have been performed to assess the optimal clinical efficacy without safety issues, as summarized in Table 3 and in the Annex I. Phase I/Ila and phase IIb doseranging studies were conducted to elicit the appropriate dose for subsequent phase III studies, for the mono-components and their combination as well.

\subsubsection{Glycopyrronium}

For the dosage of glycopyrronium, studies have shown a tendency to have a relatively flat dose/effect relationship within the different doses used [7]. In NCT01350128, four dosages of glycopyrronium MDI were used: $28.8 \mu \mathrm{g}, 14.4 \mu \mathrm{g}$, $7.2 \mu \mathrm{g}$ and $3.6 \mu \mathrm{g}$ all twice daily; and were compared to placebo MDI or open label ipratropium $34 \mu \mathrm{g} \mathrm{MDI}$, four times daily, as an active comparator for the muscarinic antagonist therapeutic class, besides being a short-acting one. After 7 days of administration, all treatments were superior to the placebo regarding the primary endpoint: $\mathrm{FEV}_{1} \mathrm{AUC}_{0-12 \mathrm{~h}}$ change from baseline at day seven, and no clear dose ranging effect was evidenced. All GP treatments were non-inferior to the active comparator. For secondary outcomes, all GP doses were superior to placebo regarding peak change from base-

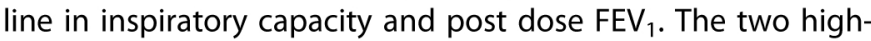
est doses of GP (i.e., 28.8 and $14.4 \mu \mathrm{g}$ ), showed the largest benefits compared to placebo in peak change from baseline IC on day 1. Furthermore, all GP doses (except the dose of $14 \mu \mathrm{g}$ ) showed a significantly higher percentage of patients reaching at least $12 \%$ of improvement in $\mathrm{FEV}_{1}$ at day 1, ranging from 52.3 to $66.7 \%$, compared with placebo. On day 7 , similar results were reported. Only the GP 28.8, 14.4 and $3.6 \mu \mathrm{g}$ doses were superior to placebo regarding $\mathrm{FEV}_{1}$ pre-dose change from baseline. No clear dose ranging was recorded on secondary outcomes, and furthermore, no safety concerns were identified within the range of doses. As a conclusion of this study, GP 28.8 and 14.4 showed the highest efficacy results in the primary outcome and almost all secondary outcomes, and no evidence was highlighted to use 28.8 rather than $14.4 \mu \mathrm{g}$, suggesting the use of GP $14.4 \mu \mathrm{g}$ twice daily as the better dose for phase III studies [22].

\subsubsection{Formoterol fumarate}

For the formoterol fumarate dosages, NCT01085045 explored, in the Part B of this study, the difference between formoterol fumarate MDI 7.2 and $9.6 \mu \mathrm{g}$ with placebo MDI and FF $12 \mu \mathrm{g}$ DPI as an active comparator. After 7 days of treatment, both FF $\mathrm{MDI}$ doses were superior to placebo in $\mathrm{FEV}_{1} \mathrm{AUC}_{0-12 \mathrm{~h}}$ $(p<0.0001)$ and were non-inferior to the open label FF $12 \mu \mathrm{g}$ DPI. For secondary outcomes (i.e. peak change from baseline $\mathrm{FEV}_{1}$ pre-dose, percentage of patients reaching at least $12 \%$ improvement in $\mathrm{FEV}_{1}$, peak change from baseline in $\mathrm{IC}$ and change in morning pre-dose $\mathrm{FEV}_{1}$ at day 7), FF MDI $7.2 \mu \mathrm{g}$ was non-inferior to $9.6 \mu \mathrm{g}$ and both FF MDI doses were non-inferior to FF $12 \mu \mathrm{g}$ DPI. However, only FF MDI $9.6 \mu \mathrm{g}$ was bio-equivalent to FF DPI $12 \mu \mathrm{g}$ [23]. Thus, FF MDI $9.6 \mu \mathrm{g}$ was considered non-inferior to Foradil ${ }^{\otimes}$ (Novartis) $12 \mu \mathrm{g}$ and selected for phase III studies [7].

\subsubsection{Glycopyrronium and formoterol fumarate combination}

Additional studies of the GFF co-formulation with different dosages were tested in studies such as in Reisner et al (NCT01085045 [23] and NCT01349816 [24]) and Tashkin et al (NCT01587079) [25], with GFF dosages ranging from $1.2 \mu \mathrm{g} /$ $9.6 \mu \mathrm{g}$ to $72 \mu \mathrm{g} / 9.6 \mu \mathrm{g}$ twice daily. In the two studies of Reisner et al, all doses of GFF were superior to placebo and/ or GP in change from baseline in $\mathrm{FEV}_{1} \mathrm{AUC}_{0-12 \mathrm{~h}}$ at day 7 and GFF was also superior to FF MDI $9.6 \mu \mathrm{g}$ in NCT01085045 [23]. In Tashkin et al, all doses of GFF were superior to GP $18 \mu \mathrm{g}$, FF 9.6 $\mu \mathrm{g}$ and TIO, except for GFF 1.2/9.6 $\mu \mathrm{g}$ that was only superior to GP $16 \mu \mathrm{g}$. However, regarding peak change from baseline in inspiratory capacity, in Tashkin et al [25], improvements were seen only compared to GP and TIO but not FF at day 7 . Similarly, for Reisner et al, no dosages of GFF were superior to FF, and only GFF 36/9.6 $\mu \mathrm{g}$ was superior to GP and $\mathrm{TIO}$, whereas GFF $72 / 9.6 \mu \mathrm{g}$ was superior only to TIO at day 7 for NCT01085045 [23]. In NCT01349816 [24], the two higher dosages were superior to GP $36 \mu \mathrm{g}$ but not compared to FF.

All GFF doses were superior in peak change $\mathrm{FEV}_{1}$ at day 7 , compared to placebo, GP $36 \mu \mathrm{g}, \mathrm{FF} \mathrm{MDI}$, and active 


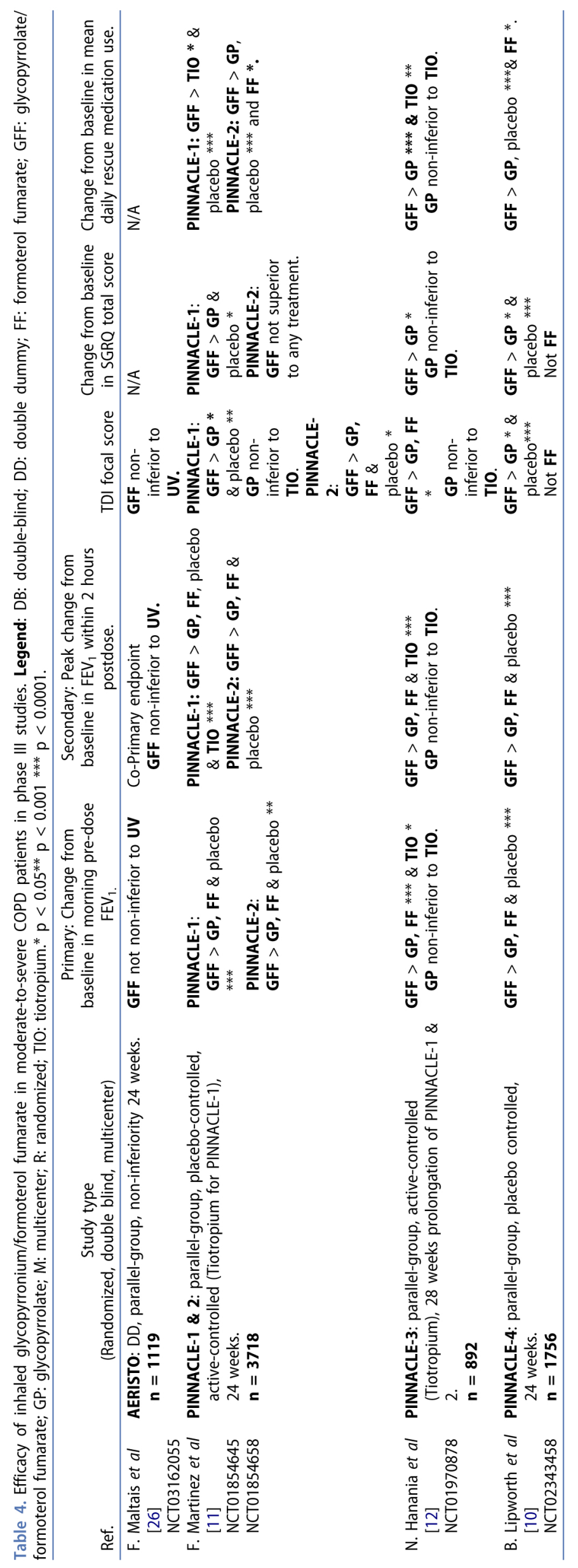


comparator (TIO and FF DPI), except for the lowest GFF dose for Tashkin et al, and GFF was only superior to GP $36 \mu \mathrm{g}$ and not FF $9.6 \mu \mathrm{g}$ for NCT01349816. When looking at the percentage of patients reaching at least $12 \%$ improvement in $\mathrm{FEV}_{1}$ at day 1, only GFF $18 / 9.6 \mu \mathrm{g}$ showed superiority to placebo, mono-components and active comparator.

Considering the change in morning pre-dose $\mathrm{FEV}_{1}$ at day 7 , Reisner et al exhibited superiority of both GFF dosages compared to GP, FF and TIO [23]. Tashkin et al showed superiority of GFF 18/9.6 $\mu \mathrm{g}$ and 2.4/9.6 $\mu \mathrm{g}$ to GP, FF and TIO but unexpectedly, GFF 9/9.6 $\mu \mathrm{g}$ and 4.6/9.6 $\mu \mathrm{g}$ were only superior to FF [25].

Furthermore, GFF 36/9.6 $\mu \mathrm{g}$ was non-inferior to GFF 72/ 9.6 $\mu \mathrm{g}$ regarding the primary outcome of the study NCT01085045 [23]. Nevertheless, studies have been focusing specifically on $\mathrm{FEV}_{1}$ to assess the clinical efficacy, for which the usefulness, as a final outcome, has been debated. An assessment of the efficacy, as performed in some phase III studies [13], through residual volume, total lung capacity or inspired capacity during effort would be more sensitive but would imply more technical constraints.

These results combined with other studies confirmed the flat dose response curve of glycopyrronium, leading to the use of GFF $18 / 9.6 \mu \mathrm{g}$ as the most likely optimal dose for phase III studies. The dosage includes two actuations of GFF pMDI (9.0/ $4.8 \mu \mathrm{g})$ twice daily. Each actuation meters $10.4 \mu \mathrm{g}$ of glycopyrrolate equivalent to $8.3 \mu \mathrm{g}$ of glycopyrronium and $5.5 \mu \mathrm{g}$ of formoterol fumarate. This metered dose is equivalent to a delivered dose (the actual dose reaching the lungs) of $7.2 \mu \mathrm{g}$ of glycopyrronium and $4.8 \mu \mathrm{g}$ of formoterol fumarate $[7,16]$.

Glycopyrronium delivered by DPI (Ultibro ${ }^{\mathrm{TM}}$ Breezhaler $^{\oplus}$ ), alone or in combination with indacaterol, is marketed for once daily administration in Europe. By contrast, MDI-based formulations of glycopyrronium (Bevespi Aerosphere ${ }^{\circledast}$, but also Gly/BDP and Gly/FF/BDP) and the Gly/BDP DPI NEXThaler ${ }^{\oplus}$ formulation are marketed for twice daily administrations.

Thus, in contrast to AUCs that will be equivalents for equal daily dose, as the PK of Glycopyrronium is linear, Cmax of single daily dose formulations will be higher, which may lead to an increase of toxicity that split twice daily dose could reduce.

\subsection{Summary of phase I \& II}

See Table 3.

\subsection{Phase III}

Efficacy of glycopyrrolate and formoterol fumarate was tested through different phase III trials: the PINNACLE program, comprising 4 studies, and the AERISTO trial, that tested the noninferiority of GFF compared to another LAMA/LABA combination available on the market.

The PINNACLE program included three 24-week randomized, double-blind, multicenter, placebo-controlled trials: PINNACLE-1 and 2 [11] and PINNACLE-4 [10]. Another 28week extension of PINNACLE-1 \& 2, named PINNACLE-3 [12], was conducted to assess the long-term efficacy and safety of the dual combination compared to placebo and active control. The study included moderate to very severe COPD patients aged $40-80$ years, with active or history of smoking superior to 10 pack-years. The requirements for patients were to have a post-bronchodilator $\mathrm{FEV}_{1} /$ forced vital capacity ratio below 0.7, $\mathrm{FEV}_{1}<80 \%$ predicted, and a post-bronchodilator $\mathrm{FEV}_{1}$ $>750 \mathrm{~mL}$ for patients with $\mathrm{FEV}_{1}<30 \%$ predicted. The main exclusion criteria were requirement for long-term oxygen therapy for $>12 \mathrm{~h} /$ day, COPD hospitalization within 3 months before screening, significant diseases other than COPD and change in smoking status during the screening period.

Patients were randomized to receive twice daily GFF MDI $18 / 9.6 \mu \mathrm{g}$ or GP MDI $18 \mu \mathrm{g}$ or FF MDI $9.6 \mu \mathrm{g}$ or placebo MDI [10-12]. In PINNACLE-1 another arm received open-label tiotropium $18 \mathrm{DPI} \mu \mathrm{g}$ once daily [11]. Patients completing the 24week PINNACLE-1 or 2, were randomly invited to participate in the PINNACLE-3 28-week extension trial [12].

The AERISTO trial was a randomized, double-blind, doubledummy, multicenter 24-week trial assessing the efficacy and safety of GFF MDI relative to umeclidinium/vilanterol dry powder inhaler (UV DPI) once daily [26]. The study population was 40-95 year-old patients diagnosed with COPD with a smoking history of at least 10 pack-years. $\mathrm{FEV}_{1} / \mathrm{FVC}$ was required to be less than 0.7 and $\mathrm{FEV}_{1}<80 \%$ predicted value. The COPD assessment test (CAT) score was required to be at least 10 . Asthmatic patients and patients with other diseases that could influence the results of the study were excluded. Patients suffering from a COPD exacerbation between screening and randomization were excluded, and were also excluded if they had not recovered from a moderate or severe COPD exacerbation before screening, for 4 or 8 weeks, respectively. Patients received twice daily GFF MDI 18/9.6 $\mu \mathrm{g}$ (also considered equivalent to glycopyrronium/formoterol fumarate 14.4/ $10 \mu \mathrm{g}$ ) or UV DPI $62.5 / 25 \mu \mathrm{g}$ once daily after randomization [26].

The key results of the two different programs are summarized in Table 4 and extensive summary of all phase III trials are detailed in Annex II.

\subsubsection{Lung function}

Glycopyrronium combined with formoterol fumarate was associated with a better improvement of lung function than placebo, monocomponents taken individually or tiotropium [10-12]. GFF was superior in change from baseline in morning pre-dose $\mathrm{FEV}_{1}$ at 24 weeks, which was the PINNACLE-1, 2 and 4 primary outcome, compared to placebo, glycopyrronium, formoterol fumarate (all $p<0.001$ ) $[10,11]$. The 28 -week extension PINNACLE-3 study showed the same results, with superiority of GFF over glycopyrronium or formoterol fumarate alone, and superiority to the open-label active comparator tiotropium $18 \mu \mathrm{g}$, i.e. Spiriva ${ }^{\circledR}(p=0.0117)$. Furthermore, glycopyrronium alone was non-inferior to tiotropium [12]. A posthoc analysis of PINNACLE-1 \& 2 showed an absence of effect of the CAT baseline score upon improvements in morning predose $\mathrm{FEV}_{1}$ [27].

GFF was associated with a higher improvement in the change from baseline in peak $\mathrm{FEV}_{1}$ within $2 \mathrm{~h}$ post dose at week 24 compared to glycopyrronium, formoterol fumarate, 
placebo and tiotropium (all $\mathrm{p}<0.0001$ ) [10-12]. Glycopyrronium itself was non-inferior to tiotropium for this endpoint in PINNACLE-3 [12]. The baseline CAT score was not associated with differences in improvements of peak $\mathrm{FEV}_{1}$ [27].

The time to onset-of-action was assessed at day 1 in PINNACLE-1, 2 and 4 and showed significant improvements of GFF compared to placebo, within 5 minutes post-dose $[10,11]$.

For the co-primary endpoints in the AERISTO trial, GFF showed non-inferiority to umeclidinium/vilanterol in the peak change from baseline in $\mathrm{FEV}_{1}$ within $2 \mathrm{~h}$ post dose over 24 weeks, but failed to achieve the non-inferiority cutoff in change from baseline in morning pre-dose $\mathrm{FEV}_{1}$ $(-87.2 \mathrm{~mL}[-117.0 ;-57.4])$ [26]. Superiority for GFF in peak change $F_{E V}$ was not demonstrated $(p=0.5516)$. Nominal non-inferiority in change from baseline in peak inspiratory capacity within 2 hours was shown, as well as nominal superiority in terms of proportion of patients with change from baseline in $\mathrm{FEV}_{1} \geq 100 \mathrm{~mL}$ at 5 min post dose on day 1 , meaning that GFF has a more rapid onset of action than UV [26]. The AERISTO trial exhibited efficacy results that were lower on the GFF arm compared to previous PINNACLE studies (around 20\% lower: $299 \mathrm{~mL}$ vs 364-375 mL). Maltais et al, provided some hypothesis to explain this point: difference between baseline populations and a different study design for the trial with a doubledummy condition. Nevertheless, no factors were fully explaining the difference between these trials [26].

\subsubsection{Transition dyspnea index (TDI) focal score}

Glycopyrronium/formoterol fumarate was associated with a better improvement in dyspnea than placebo and glycopyrronium in all PINNACLE trials and better than formoterol in PINNACLE-2 and 3 only [10-12]. Different approaches were used to assess the transition dyspnea index focal score: for PINNACLE-1, 2, and 3 the Self-Administered Computerized TDI (SAC-TDI) focal score was assessed, and intervieweradministered TDI focal scores were assessed for PINNACLE-4. In PINNACLE-1, the dual combination of GFF improved TDI score only compared to placebo and glycopyrronium, whereas in PINNACLE-2, GFF was superior to placebo, GP and formoterol fumarate as well. Glycopyrronium alone was non-inferior to tiotropium in PINNACLE-1, but GFF did not meet the superiority criteria compared to the active comparator tiotropium $[7,11]$. The same results were obtained in the PINNACLE-4 using a different approach in the reporting of the TDI focal score. GFF was superior to placebo and glycopyrronium after 24 weeks in improvements of TDI focal score, but not to formoterol fumarate alone $(p=0.2530)$ [10]. Furthermore, more patients reached the minimal clinical important difference (MCID, meaning $\geq 1$ unit) for TDI focal score with GFF than placebo $(p<0.0001)$ or GP $(p=0.0015)$ [10]. However, in the 28-week extension PINNACLE-3 study, GFF significantly improved the reported breathlessness compared to each mono-component taken individually, i.e. glycopyrronium and formoterol fumarate. As seen in PINNACLE-1, GP was noninferior to tiotropium but GFF was not superior to the active

Table 5. Safety of glycopyrronium/formoterol fumarate in clinical trials. Legend: 'Yes': safety parameter evaluated. 'N/A': Safety parameter not evaluated. AE: adverse event; DPI: dry powder inhaler; ECG: electrocardiogram; FF: formoterol fumarate; GFF: glycopyrronium formoterol fumarate; GP: glycopyrronium; SAEs: serious adverse events; TEAE: treatment emergent adverse event; TIO: tiotropium; TQT: thorough QT; URTI: upper respiratory tract infection; UV: umeclidinium vilanterol; $\geq \% 1$ TEAE: \% of patients who presented at least one treatment emerged adverse event.

\begin{tabular}{|c|c|c|c|c|c|c|}
\hline Safety Outcomes & F. Maltais et al [26] & B. Lipworth et al [10] & $\begin{array}{r}\text { F. Martinez et al [1 } \\
1 \& 2\end{array}$ & (PINNACLE- & N. Hanania et al [12] & $\begin{array}{c}\text { G. Ferguson et al } \\
{[15]}\end{array}$ \\
\hline ECG & $\mathrm{N} / \mathrm{A}$ & Yes & $\begin{array}{r}\text { Yes }(+24-\mathrm{hr} \\
\text { PINNAC }\end{array}$ & $\begin{array}{l}\text { Iter for } \\
-2)\end{array}$ & Yes & Yes + TQT study \\
\hline Vital Signs & N/A & Yes & Yes & & Yes & Yes \\
\hline Clinical laboratory tests & $\mathrm{N} / \mathrm{A}$ & Yes & Yes & & Yes & Yes \\
\hline $\begin{array}{l}\geq \% 1 \text { TEAE (\% related to } \\
\text { study treatment) }\end{array}$ & $\begin{array}{l}\text { GFF } 40.9(1.3) \\
\text { UV } 44.9(0.5)\end{array}$ & $\begin{array}{l}\text { GFF } 55.5(10.0) \\
\text { GP } 52.7(10.8) \\
\text { FF } 53.3(9.6) \\
\text { placebo } 55.7(9.8)\end{array}$ & $\begin{array}{c}\text { GFF } 62.9(12.4) \\
\text { GP } 58.8(12.4) \\
\text { FF } 59.5(13.1) \\
\text { placebo } 62.7 \\
(14.1) \\
\text { TIO } 62.7(10.2)\end{array}$ & $\begin{array}{c}\text { GFF } 56.1 \\
(10.2) \\
\text { GP 53.5 } \\
(9.8) \\
\text { FF 54.1 } \\
(8.9) \\
\text { placebo } \\
52.5 \\
(6.7)\end{array}$ & $\begin{array}{c}\text { GFF } 64.6(12.5) \\
\text { GP } 59.9(12.2) \\
\text { FF } 60.4(11.9) \\
\text { TIO } 69.2(12.0)\end{array}$ & $\begin{array}{c}\text { GFF } 36.7(10.0) \\
\text { GP } 32.8(20.7) \\
\text { FF } 28.3(20.0) \\
\text { FF DPI } 28.8 \\
(11.9)\end{array}$ \\
\hline SAEs (\%) & $\begin{array}{l}\text { GFF } 5.8 \\
\text { UV } 7.2\end{array}$ & $\begin{array}{c}\text { GFF } 9.6 \\
\text { GP } 7.2 \\
\text { FF } 8.3 \\
\text { placebo } 8.1\end{array}$ & $\begin{array}{c}\text { GFF } 8.4 \\
\text { GP } 8.0 \\
\text { FF } 6.4 \\
\text { placebo } 7.3 \\
\text { TIO } 8.0\end{array}$ & $\begin{array}{c}\text { GFF } 7.1 \\
\text { GP } 8.4 \\
\text { FF } 8.4 \\
\text { placebo } \\
6.7\end{array}$ & $\begin{array}{c}\text { GFF } 11.0 \\
\text { GP } 10.1 \\
\text { FF } 8.8 \\
\text { TIO } 10.9\end{array}$ & $\begin{array}{l}\text { GFF } 1.7 \\
\text { GP } 0 \\
\text { FF } 1.7 \\
\text { FF DPI } 1.7\end{array}$ \\
\hline $\begin{array}{l}\text { Withdrawal due to } \mathrm{AE} \\
\text { (\%) }\end{array}$ & $\begin{array}{l}\text { GFF } 4.0 \\
\text { UV } 3.6\end{array}$ & $\begin{array}{c}\text { GFF } 4.9 \\
\text { GP } 5.3 \\
\text { FF } 5.0 \\
\text { placebo } 4.3\end{array}$ & $\begin{array}{c}\text { GFF } 7.4 \\
\text { GP } 7.3 \\
\text { FF } 4.9 \\
\text { placebo } 6.4 \\
\text { TIO } 4.9\end{array}$ & $\begin{array}{c}\text { GFF } 4.9 \\
\text { GP } 4.8 \\
\text { FF } 5.7 \\
\text { placebo } \\
8.5\end{array}$ & $\begin{array}{c}\text { GFF } 7.8 \\
\text { GP } 7.2 \\
\text { FF } 6.0 \\
\text { TIO } 6.2\end{array}$ & $\begin{array}{l}\text { GFF } 3.3 \\
\text { GP } 1.7 \\
\text { FF } 0 \\
\text { FF DPI } 3.4\end{array}$ \\
\hline $\begin{array}{l}\text { Most common AE among } \\
\text { GFF group }(>2 \%)\end{array}$ & $\begin{array}{l}\text { Headache, } \\
\text { nasopharyngitis, } \\
\text { COPD, viral } \\
\text { URTI, back pain, } \\
\text { hypertension. }\end{array}$ & $\begin{array}{c}\text { Viral URTI, URTI, COPD, } \\
\text { headache, } \\
\text { hypertension, } \\
\text { cough, dyspnea, } \\
\text { back pain, } \\
\text { pharyngitis. }\end{array}$ & $\begin{array}{r}\text { Nasopharyngitis, } \\
\text { bronchitis, pneu } \\
\text { abscess, coug } \\
\text { COPD, back pai } \\
\text { nausea, diarrh } \\
\text { failur }\end{array}$ & $\begin{array}{l}\text { TI, sinusitis, } \\
\text { onia, tooth } \\
\text { dyspnea, } \\
\text { arthralgia, } \\
\text { a, cardiac }\end{array}$ & $\begin{array}{l}\text { Nasopharyngitis, cough, URTI, } \\
\text { urinary tract infection, COPD, } \\
\text { sinusitis, back pain, dyspnea, } \\
\text { pneumonia, bronchitis, nausea, } \\
\text { arthralgia. }\end{array}$ & $\begin{array}{l}\text { COPD, dizziness, } \\
\text { hypertension, } \\
\text { hypokalemia, } \\
\text { tachycardia, } \\
\text { sinus pause }\end{array}$ \\
\hline
\end{tabular}


comparator [12]. The odds ratio of reaching the MCID in SACTDI focal score for the GFF group was only numerically superior to monocomponents and active comparator.

In the AERISTO trial, GFF was considered non-inferior to UV for the TDI focal score as the confidence intervals bounds were within the non-inferiority margin and the difference was not clinically meaningful [26].

\subsubsection{Quality of life}

In the PINNACLE trials, glycopyrronium/formoterol fumarate was associated with improvements in health-related quality of life (HR-QoL) using the St. George's Respiratory Questionnaire (SGRQ) total score. PINNACLE-1 showed improvements in SGRQ total score for GFF compared to placebo and GP $(p<0.01)$ but not FF. PINNACLE-2 did not show any difference between treatments. The odds ratio of reaching the MCID for SGRQ total score ( $\geq 4$ units) at 24 weeks in the GFF group was superior to placebo $(O R=1.49)$ and $G P(O R=1.39)$ in the intent-to-treat population [11]. A post-hoc study of PINNACLE$1 \& 2$ showed that the percentage of patients who reached the MCID among those with baseline CAT scores equal to or higher than 20 was superior with GFF versus GP and FF (both $p<0.05)$ and placebo $(p<0.01)$, suggesting a greater benefit in more severe patients [27]. PINNACLE-4 exhibited similar results, with GFF being superior to placebo and GP in improving SGRQ total score. The percentage of patients reaching the MCID was statistically superior in GFF compared to placebo, and only numerically superior compared to GP [10].

The PINNACLE-3 study showed the same results as PINNACLE-1 \& 2, with GFF being superior to GP regarding change from baseline in SGRQ total score and numerically superior to FF and tiotropium. The odds ratio for achieving an improvement equal to or greater than the MCID was superior for GFF when compared to GP (OR = 1.27, $p=0.0140)$, numerically superior to $F F(O R=1.19, p=0.0760)$ but not superior to tiotropium. Glycopyrronium alone did not show non-inferiority compared to tiotropium [12].

\subsubsection{Time-to-first exacerbation and rescue medication}

use

The time-to-first moderate-to-severe exacerbation was assessed in the PINNACLE trials. An improvement in favor of GFF was evidenced when compared to GP and placebo. In the post-hoc analysis of PINNACLE-1 \& 2, Martinez et al, showed that the higher the CAT score at baseline, the higher the annual risk rate of exacerbation. In this regard, GFF was more efficient than GP and placebo in reducing the high CAT score associated-increased risk. In particular, in the population with baseline CAT scores above 15, the hazard ratio of time to first moderate or severe exacerbation for GFF was 0.69 compared to GP ( $p<0.01), 0.77$ compared to FF $(p<0.05)$ and 0.66 compared to placebo $(p<0.01)$ [27]. Additionally, in PINNACLE-3, the time to first moderate-to-severe COPD exacerbation was longer for GFF users compared to monocomponents and similar compared to tiotropium [12].

The combination of glycopyrrolate and formoterol fumarate significantly reduced the mean daily rescue medication in PINNACLE trials [10-12]. In PINNACLE-1, GFF reduced the daily rescue medication use of albuterol compared to placebo $(p<0.0001)$ and tiotropium $(p<0.05)$; in PINNACLE-2, GFF was superior to GP, placebo $(p<0.0001)$ and FF $(p<0.05)$ over 24 weeks of treatment [11]. PINNACLE-4 showed similar results for GFF in comparison with GP, placebo and FF [10] in reducing the number need of puffs per day, as shown in Table 4.

The extension study PINNACLE-3 showed that GFF was superior to GP $(p<0.0001)$ and tiotropium $(p=0.0002)$ the open-label comparator. Glycopyrronium, by itself, was noninferior to tiotropium [12].

\subsection{Summary of phase III}

See Table 4

\section{Post marketing surveillance}

\subsection{Clinical safety}

During the development of GFF MDI, 4358 patients with COPD were exposed to the drug or its mono-components: glycopyrronium or formoterol fumarate [7](Table 5 and Annex III). Four pivotal phase III studies have been performed (PINNACLE-1, 2 3 and 4) with exposure up to 52 weeks. Within those trials, $62.9 \%, 56.1 \%, 64.6 \%$ and $55.5 \%$ of patients in the GFF group reported one or more treatment emergent adverse events (TEAE) and around $10-12 \%$ of them were related to the study drug by the investigator [10-12]. The majority of those adverse events (AEs) were mild to moderate, with nasopharyngitis, cough, upper respiratory tract infection and urinary tract infection being the most common, with incidences similar to each mono-component, placebo or tiotropium (Spiriva ${ }^{\oplus}$, Boehringer Ingelheim) [7,10-12].

Serious adverse events (SAE) were reported in trials with similar incidences between groups. After COPD worsening, pneumonia was the most commonly reported SAE, with higher incidence in GFF and GP than in FF-treated patients in the 24-week or 52-week trials and was the only SAE with higher incidence [7,10-12]. However, this finding was observed in pooled data of PINNACLE-1 \& 2, but was not true in PINNACLE-2 alone. In addition, the incidence of this SAE was low during all pivotal studies $(<2 \%)$ and likely a chance finding. During clinical studies, no clear explanation was provided to understand this difference, post-marketing surveillance will be of interest to elucidate whether there is a correlation or only a random association within COPD patients that are frequently having pneumonia.

11 deaths occurred during the 52 week treatment period of PINNACLE-1 and -2 , combined with PINNACLE-3, with 4 deaths in GFF MDI groups. Additionally, there was an extra death on GFF and an extra death on GP that occurred within 14 days of last dose which are not counted in these totals. The analysis of those deaths and the low incidence level is in accordance with a mortality rate expected in this type of population, i.e. moderate-to-severe COPD patients with multiple co-morbidities [7].

PINNACLE-4 showed similar trends with $55.5 \%$ of the GFF population exerting one or more TEAEs, with $10.0 \%$ related to the drug and $9.6 \%$ reported as SAE. The most commons AEs 
were also Upper Respiratory Tract Infection, headache, cough, COPD worsening, dyspnea and nasopharyngitis [10].

The AERISTO trial reported similar tolerability of GFF versus umeclidinium/vilanterol combination (Anoro Ellipta ${ }^{\oplus}$, GlaxoSmithKline). Rates of declared adverse events were similar, (40.9 vs $44.9 \%$ respectively), as were SAE (5.8\% vs $7.2 \%$ ), and the most common AEs were also similar overall (headache, nasopharyngitis, COPD, viral URTI, back pain, hypertension) [26].

The Japanese safety study showed no difference in tolerability compared with the overall population [18].

Adverse events of major interest, specifically related to cardiovascular safety, were explored in three trials [11], including a TQT study [15]. Those studies did not exhibit any changes in 24-h mean, maximum, minimum, nighttime nor daytime heart rate. The incidence of specific supraventricular or ventricular ectopic events was the same as in the placebo groups, and the Fredericia's corrected QT (QTCF) interval was not clinically prolonged and similar across treatment groups.

\subsection{Global pharmacovigilance database analysis}

Bevespi Aerosphere ${ }^{\circledR}$ (glycopyrrolate/formoterol fumarate) is a new treatment for chronic obstructive pulmonary disease. Literature data on Adverse Drug Reactions (ADRs) remain sparse in real life settings. We interrogated a global adverse drug reaction database (Vigibase) in order to better characterize ADRs related to 'real-life' use of Bevespi Aerospere ${ }^{\circledR}$.

Individual case safety reports (ICSRs) associated to Bevespi Aerosphere $^{\circledast}$ were extracted from Vigibase ${ }^{\circledast}$. Characteristics of ICSRs, type of ADRs according to MedDRA classification (SOC and PT) and ICSR seriousness are described.

A total of 692 ICSRs were identified with 2722 ADRs. Respiratory, thoracic, and mediastinal disorders ( $n=321$, 46.4\%) were the most frequent ADRs (mainly 'dyspnea' ( $n=143,20.7 \%)$, cough $(n=94,13.6 \%)$ and chronic obstructive pulmonary disease $(n=57,8.2 \%)$ ); followed by 'injury, poisoning and procedural complications' ( $n=281,40.6 \%$ ) (mainly 'off label use' and 'Intentional product misuse'). Approximately 1 out of 3 were 'General disorders and administration site conditions' including 'drug ineffective' ( $n=46$, $6.6 \%)$. Overall, 139 reports were classified as 'serious' (20.1\%), including 20 deaths. Bevespi Aerosphere ${ }^{\circledR}$ was the only suspect drug in 66 serious cases (47.5\%) and in 18 of 20 deaths (90\%).

Adverse reactions reported with Bevespi resemble those already known for other drugs of this ATC class.

However, more data will be needed to better characterize the 'real-life' safety profile.

\section{Regulatory affairs}

The FDA approved GFF on 04/25/2016 for the long-term, maintenance treatment of airflow obstruction in patients with COPD [28].

The EMA assessment report considered the benefit-risk balance of GFF favorable as a maintenance bronchodilator treatment to relieve symptoms in adult patients with COPD and is therefore authorized in the EU since 12/18/2018 [7].

The PMDA (Japan) approved the GFF on $06 / 18 / 2019$ for the relief of symptoms secondary to airway obstructive disorder in patients with COPD who require a combination therapy of LAMA and LABA [29].

The NMPA (China) approved the GFF on $05 / 18 / 2020$ as a maintenance treatment to relieve symptoms in patients with COPD, including chronic bronchitis and/or emphysema.

\section{Conclusion}

In conclusion, glycopyrrolate/formoterol fumarate fixed dose combination, used twice daily, is the only currently approved pressurized metered dose inhaler LAMA/LABA fixed dose combination with proven efficacy and safety in COPD patients. This drug offers a new galenic form in the therapeutic arsenal for the management of symptoms in COPD, for clinicians and COPD patients. The exhaustive comparison to other formulations of LAMA/LABA FDC is required and will be worthwhile to assess the position of this FDC relative to its competitors.

\section{Expert opinion}

Although the current unmet need in COPD is still huge and only partly covered by the existing medications, the new LAMA-LABA fixed combination deserves attention. In the therapeutic arsenal dedicated to manage COPD, LAMA-LABA fixed combinations are occupying a very special place. The main question is why and how can they reduce rates of exacerbations despite being ICS-free. Eosinophil-guided ICS was found to be a correct strategy in nearly all studies except one. Accordingly, most guidelines support the use of LAMA-LABA fixed combination for GOLD $B$ and eventually $D$, i.e. in symptomatic patients with few or no exacerbations, or if exacerbations seem to be non-eosinophilic driven, acknowledging that this is still more of a suggestion than a guidance. Intrinsic antiinflammatory properties of LABA and LAMA have also been suggested, even though the exact underlying mechanisms remain elusive. The fixed-dose combination glycopyrrolate and formoterol fumarate achieved key outcomes for achieving approval in terms of lung function, quality of life, symptoms, and exacerbation rates, above each mono-component. Its safety profile was in line with comparators. Interesting mechanistic and physiological studies provide insights in the lung deflation offered by these drugs through a preferentialperipheral delivery. Through an innovative pMDI Aerosphere inhaler both the LAMA and LABA are delivered by an easy to use device. Given twice daily, this option looks efficient and safe, not necessarily only for patients preferring $\mathrm{pMDI}$.

The future will help understanding whether blood eosinophil counts should be taken into account or not for restricting LABA-LAMA FDC use in patients who are still symptomatic despite receiving one mono-component. Furthermore, the impact of ICS withdrawal on the addressing of clinical outcomes still needs to be explored [30,31]. Whether these potent combinations are exerting beneficial roles in preventing the onset of comorbidities, and in particular of cardiovascular comorbidities, are important questions to address in the 
future. Triple fixed dose combinations are naturally creating growing interest given the power of their pivotal studies and the potentially relevant outcomes tested [32-36]. It appears unlikely that guidelines will include ICS everywhere. On the other hand, the real world, in particular at the primary care level - if prescriptions are not restricted - would prefer using triple therapy instead of ICS-free combinations because of the rise of the $\mathrm{ACO}$ concept and the complexity of discriminating asthma from COPD in the clinic. In this perspective, HCP would be reluctant to miss an indication of ICS in patients at risk of severe exacerbations, i.e. to miss an asthma trait in a patient whose condition more closely resembles COPD. This already seems to overweigh the potential harmfulness of ICS in terms of pneumonia, for example. This is a potential threat for GFF and LABA-LAMA FDC in general, in the long-term.

\section{Acknowledgments}

The Uppsala Monitoring Centre has provided the data but the study results and conclusions are those of the authors and not necessarily those of the Uppsala Monitoring Centre, National Centers, or WHO.

\section{Declaration of interest}

A Bourdin reports grants from AstraZeneca, during the conduct of the study; grants, personal fees, non-financial support and other from AstraZeneca, grants, personal fees, non-financial support and other from Boeringher Ingelheim, grants, personal fees, non-financial support and other from GlaxoSmithKline, personal fees, non-financial support and other from Novartis, personal fees and non-financial support from Teva, personal fees, non-financial support and other from Regeneron, personal fees, nonfinancial support, and other from Chiesi Farmaceuticals, grants, personal fees, non-financial support and other from Actelion, personal fees from Gilead, non-financial support and other from Roche, other from Nuvaira, from null, outside the submitted work. The authors have no other relevant affiliations or financial involvement with any organization or entity with a financial interest in or financial conflict with the subject matter or materials discussed in the manuscript apart from those disclosed.

\section{Funding}

This paper was not funded.

\section{Reviewer disclosures}

A reviewer on this manuscript has disclosed that they have provided lectures or other expert work to the manufacturers of all LAMA-LABAcombinations e.g. AstraZeneca, GlaxoSmithKline, Boehringer-Ingelheim, Novartis. Peer reviewers on this manuscript have no relevant financial or other relationships to disclose.

\section{Scientific accuracy review}

AstraZeneca provided a scientific accuracy review at the request of the journal editor

\section{References}

1. Global Initiative for Chronic Obstructive Lung Disease. Global initiative for chronic obstructive lung disease report 2020 [Internet]. 2020 [cited 2020 Apr 2]. Available from: http://goldcopd.org/

2. Soriano JB, Abajobir AA, Abate $\mathrm{KH}$, et al. Global, regional, and national deaths, prevalence, disability-adjusted life years, and years lived with disability for chronic obstructive pulmonary disease and asthma, 1990-2015: a systematic analysis for the global burden of disease study 2015. Lancet Respir Med. 2017;5:691-706.

3. Wang C, Xu J, Yang L, et al. Prevalence and risk factors of chronic obstructive pulmonary disease in China (the China pulmonary health $[\mathrm{CPH}]$ study): a national cross-sectional study. Lancet. 2018;391:1706-1717.

4. Criner GJ, Celli BR, Brightling CE, et al. Benralizumab for the prevention of COPD exacerbations. N Engl J Med. 2019;381:1023-1034.

5. Ohgoda $\mathrm{O}$, Robinson IN. Toxicological evaluation of DSPC (1,2-distearoyl-sn-glycero-3-phosphocholine). Fundam Toxicol Sci. 2020;7:55-76.

6. Doty $A$, Schroeder J, Vang $K$, et al. Drug delivery from an innovative LAMA/LABA co-suspension delivery technology fixed-dose combination mdi: evidence of consistency, robustness, and reliability. AAPS PharmSciTech [Internet]. 2018;19:837-844. Available from: http://dx.doi.org/10.1208/s12249-017-0891-1

7. European Medicines Agency. Assessment report - Bevespi Aerosphere [Internet]. 2018 [cited 2020 Apr 2]. Available from: https://www.ema.europa.eu

8. Taylor G, Warren S, Dwivedi S, et al. Gamma scintigraphic pulmonary deposition study of glycopyrronium/formoterol metered dose inhaler formulated using co-suspension delivery technology. Eur J Pharm Sci [Internet]. 2018;111:450-457. Available from: https:// doi.org/10.1016/j.ejps.2017.10.026

9. Corcoran TE. Imaging in aerosol medicine. Respir Care. 2015;60:850-855.

10. Lipworth BJ, Collier DJ, Gon Y, et al. Improved lung function and patient-reported outcomes with co-suspension delivery technology glycopyrrolate/formoterol fumarate metered dose inhaler in COPD: A randomized phase III study conducted in Asia, Europe, and the USA. Int J COPD. 2018;13:2969-2984.

11. Martinez FJ, Rabe KF, Ferguson GT, et al. Efficacy and safety of glycopyrrolate/formoterol metered dose inhaler formulated using co-suspension delivery technology in patients with COPD. Chest [Internet]. 2017;151:340-357. Available from: http://dx.doi.org/10. 1016/j.chest.2016.11.028

12. Hanania NA, Tashkin DP, Kerwin EM, et al. Long-term safety and efficacy of glycopyrrolate/formoterol metered dose inhaler using novel co-suspension ${ }^{T M}$ delivery technology in patients with chronic obstructive pulmonary disease. Respir Med [Internet]. 2017;126:105-115. Available from: http://dx.doi.org/10.1016/j. rmed.2017.03.015

13. De Backer W, De Backer J, Vos W, et al. A randomized study using functional respiratory imaging to characterize bronchodilator effects of glycopyrrolate/formoterol fumarate delivered by a metered dose inhaler using co-suspension delivery technology in patients with COPD. Int J COPD. 2018;13:2673-2684.

14. Reisner C, Gottschlich G, Fakih F, et al. 24-h bronchodilation and inspiratory capacity improvements with glycopyrrolate/formoterol fumarate via co-suspension delivery technology in COPD. Respir Res. 2017;18:1-11.

15. Ferguson GT, Reisner C, Pearle J, et al. Cardiovascular safety profile of a fixed-dose combination of glycopyrrolate and formoterol fumarate delivered via metered dose inhaler using co-suspension delivery technology. Pulm Pharmacol Ther [Internet]. 2018;49:67-74. Available from: https://doi.org/10.1016/j.pupt.2018. 01.007

16. European Medicines Agency. Annex I: summary of product characteristics - Bevespi aerosphere [Internet]. 2019 [cited 2020 Apr 2]. Available from: https://www.ema.europa.eu/

17. Ferguson GT, Rodriguez-Roisin R, Reisner $C$, et al. Pharmacokinetics of glycopyrronium/formoterol fumarate dihydrate delivered via 
metered dose inhaler using co-suspension delivery technology in patients with moderate-to-very severe COPD. Int J COPD. 2018;13:945-953.

18. Reisner C, Miller J, DePetrillo P, et al. Pharmacokinetics and safety of a single dose of the novel LAMA/LABA fixed-dose combination of glycopyrronium/formoterol fumarate dihydrate metered dose inhaler, formulated using co-suspension delivery technology, in Japanese healthy subjects. Pulm Pharmacol Ther [Internet]. 2018;53:33-38. Available from: https://doi.org/10.1016/j.pupt.2018. 09.005

19. Fakih F, Spangenthal S, Sigal B, et al. Randomized study of the effects of aerochamber plus ${ }^{\circledast}$ flow-vu ${ }^{\oplus}$ on the efficacy, pharmacokinetics and safety of glycopyrronium/formoterol fumarate dihydrate metered dose inhaler in patients with chronic obstructive pulmonary disease. Respir Med [Internet]. 2018;138:74-80. Available from: https://doi.org/10.1016/j.rmed.2018.03.033

20. Dumitras S, Sechaud R, Drollmann A, et al. Effect of cimetidine, a model drug for inhibition of the organic cation transport (OCT2/ MATE1) in the kidney, on the pharmacokinetics of glycopyrronium. Int J Clin Pharmacol Ther. 2013;51:771-779.

21. Mariotti F, Ciurlia G, Spaccapelo L, et al. A two-period open-label, single-dose crossover study in healthy volunteers to evaluate the drug-drug interaction between cimetidine and inhaled extrafine CHF 5993. Eur J Drug Metab Pharmacokinet. 2017;42:269-279.

22. Kerwin EM, Spangenthal S, Kollar C, et al. A phase Ilb randomized, chronic-dosing, incomplete block, cross-over study of glycopyrronium, delivered via metered dose inhaler, compared with a placebo and an active control in patients with moderate-tosevere COPD. Respir Res. 2018;19:1-13.

23. Reisner C, Fabbri LM, Kerwin EM, et al. A randomized, seven-day study to assess the efficacy and safety of a glycopyrrolate/formoterol fumarate fixed-dose combination metered dose inhaler using novel co-suspension ${ }^{\mathrm{TM}}$ delivery technology in patients with moderate-tovery severe chronic obstructive. Respir Res [Internet]. 2017;18:1-13. Available from: http://dx.doi.org/10.1186/s12931-016-0491-8

24. Reisner C, Pearle J, Kerwin EM, et al. Efficacy and safety of four doses of glycopyrrolate/formoterol fumarate delivered via a metered dose inhaler compared with the monocomponents in patients with moderate-to-severe COPD. Int J COPD. 2018;13:1965-1977.

25. Tashkin DP, Martinez FJ, Rodriguez-Roisin R, et al. A multicenter, randomized, double-blind dose-ranging study of glycopyrrolate/ formoterol fumarate fixed-dose combination metered dose inhaler compared to the monocomponents and open-label tiotropium dry powder inhaler in patients with moderate-to-severe CO. Respir Med [Internet]. 2016;120:16-24. Available from: http://dx.doi.org/ 10.1016/j.rmed.2016.09.012
26. Maltais F, Ferguson GT, Feldman GJ, et al. A randomized, double-blind, double-dummy study of glycopyrrolate/formoterol fumarate metered dose inhaler relative to umeclidinium/vilanterol dry powder inhaler in COPD. Adv Ther. 2019;36:2434-2449.

27. Martinez FJ, Fabbri LM, Ferguson GT, et al. Baseline symptom score impact on benefits of glycopyrrolate/formoterol metered dose inhaler in COPD. Chest [Internet]. 2017;152:1169-1178. Available from: https://doi.org/10.1016/j.chest.2017.07.007

28. Center for Drug Evaluation and Research. Approval letter for Bevespi [Internet]. 2016 [cited 2020 Apr 2]. Available from: http:// www.accessdata.fda.gov

29. Pharmaceuticals and Medical Devices Agency. New drugs approved in april 2019 - november 2019 [Internet]. 2019 [cited 2020 Apr 2]. Available from: https://www.pmda.go.jp

30. Magnussen $H$, Disse $B$, Rodriguez-Roisin $R$, et al. Withdrawal of inhaled glucocorticoids and exacerbations of COPD. N Engl J Med. 2014;371:1285-1294.

31. Watz H, Tetzlaff $\mathrm{K}$, Wouters EFM, et al. Blood eosinophil count and exacerbations in severe chronic obstructive pulmonary disease after withdrawal of inhaled corticosteroids: A post-hoc analysis of the WISDOM trial. Lancet Respir Med [Internet]. 2016;4:390-398. Available from: http://dx.doi.org/10.1016/S2213-2600(16)00100-4

32. Papi $A$, Vestbo J, Fabbri L, et al. Extrafine inhaled triple therapy versus dual bronchodilator therapy in chronic obstructive pulmonary disease (TRIBUTE): a double-blind, parallel group, randomised controlled trial. Lancet. 2018;391:1076-1084.

33. Vestbo J, Papi A, Corradi $M$, et al. Single inhaler extrafine triple therapy versus long-acting muscarinic antagonist therapy for chronic obstructive pulmonary disease (TRINITY): a double-blind, parallel group, randomised controlled trial. Lancet. 2017;389:1919-1929.

34. Ferguson GT, Rabe KF, Martinez FJ, et al. Triple therapy with budesonide/glycopyrrolate/formoterol fumarate with co-suspension delivery technology versus dual therapies in chronic obstructive pulmonary disease (KRONOS): a double-blind, parallel-group, multicentre, phase 3 randomised controlled tr. Lancet Respir Med [Internet]. 2018;6:747-758. Available from: http://dx.doi.org/10.1016/S2213-2600(18)30327-8

35. Rabe KF, Martinez FJ, Ferguson GT, et al. A phase III study of triple therapy with budesonide/glycopyrrolate/formoterol fumarate metered dose inhaler 320/18/9.6 $\mu \mathrm{g}$ and 160/18/9.6 $\mu \mathrm{g}$ using cosuspension delivery technology in moderate-to-very severe COPD: the ETHOS study protocol. Respir Med [Internet]. 2019;158:59-66. Available from: https://doi.org/10.1016/j.rmed.2019.08.010

36. Rabe KF, Martinez FJ, Ferguson GT, et al. Triple inhaled therapy at two glucocorticoid doses in moderate-to-very-severe COPD. N Engl J Med. 2020;383:35-48. 